\title{
PROBABILISTIC MODEL ON BUYING DECISION OF HIGHER EDUCATION SERVICES
}

\author{
Associate Professor Radu Lucian Blaga, Ph.D. \\ "Vasile Goldiş" Western University of Arad \\ E-mail: buteniradu@yahoo.com \\ Lecturer Alexandru Blaga, Ph.D. \\ "Vasile Goldiş" Western University of Arad
}

(Received: March 2018; Accepted: May 2018)

\begin{abstract}
Buying decisions are determined by two key factors: endogenous factor that belongs to the buyer (which is present at least the attitudinal variable) and exogenous factors such demo-economic, sociological, psychological, marketing mix, linked all more or less by the product or the service offered for purchase and consumption. The study aims to use Rasch's model to express the likelihood that a consumer will make the decision to purchase a higher educational service. Applied to item solving, Rasch probabilistic model, on which the research methodology study is largely supported, states that the probability of success in solving an item depends on two factors. The one belongs to that who solves the item - the human factor, called the latent trait, and the other belongs to the item, called the facility of the item The purchase decision approach using the Rasch model results validity is mainly based on the isometry of the two situations The results of the study describe behavioral probability situations where customers who make university education services purchasing decisions can themselves be found. We recommend the educational marketing strategies based on the analysis made on the applied model, which may increase the students' enrolled number in a particular university.
\end{abstract}

Key words: Rasch's probabilistic model, buying decision, higher education services, brand, attitude.

JEL CLASSIFICATION: M37, C59, I21

\section{Introduction}

Broadly speaking, education has an abstract character because it is an intangible, inseparable service which is especially characterized by a low standardization and uniformity. Education is described by the specific literature, as involving in the provision of the service, highly specialized elements (qualified personnel - people) and less than high touch elements (equipment).

The benefits of education services will be strongly felt in the career (success or failure) and the future of the followers. Instead, the material and psychological costs required to complete a form of higher education are increasing. In this 
context, it is necessary to make a series of decisions, usually unscheduled, which refer to new situations in which the client (the one enrolling in a university) can be found. These situations cause powerful psychological and financial implications for the individual. Because there is no precedent, the buying decision involves greater risk and has a more complicated structure that covers an increasingly fragmented market of education services.

On the other hand, the field of consumer behavior is widening, mainly due to the development and diversification of the service sector, predominantly in the education domain. Taking into account the motivational, behavioral and cognitive theoretical contributions, the consumer behavior can be described as a complex system of manifestations, attitudes, motivations and decisions. Combining individual circumstances and the psychological ones, buying decisions will be influenced as reactions of the individual to the various endogenous and exogenous variables.

In this context, the paper seeks to identify the chances of purchasing (selecting) a higher education service, depending on the university's brand, with the involvement of the endogenous factor - the attitude of the buyer towards education and its implications in social life, but also of certain dimensions of the brand, as exogenous nature - the attributes of the education services and the benefits offered by the brand of the university.

The study objectives are to identify and describe likely behavioral situations, in which students (high school graduates) can be found in choosing such services, using Rasch's probabilistic model in making the buying decision. Recommendations on educational marketing strategies are deduced from the study of the characteristic function attached to the purchasing event.

The development of applications in the field of higher education is recommended not only by the specificity of the service, but also by the situation in which the Romanian society and the European one are today from an educational perspective. On the Central Intelligence Agency web site - www.cia.gov we can read: "The population pyramid in Romania in the year 2016 shows that the age range of 15-24 years is the narrowest, both for women and men, with just over 1.200 thousand inhabitants for each gender. The population growth rate in 2017 was estimated at $0,33 \%$ ".

The NEETs indicator in 2016 (EU 28) for the age range of 20-24 years is 16,7\% of the active population and it is over $18 \%$ of the active population, for the age range of 25-34 years. In Romania, the NEETs indicator in 2016, according to the statistics of the European Commission - Eurostat shows higher values: 23,6\% for the age range of $20-24$ years; $24,7 \%$ for the age group 25-29 years, respectively $22,3 \%$ for the age range of $30-34$ years. 
The data presented above is obviously an alarm signal. The number of young people who will be educated mainly in university education will be drastically reduced, thus increasing competition on this segment. Moreover, at national and European level, there is a need for urgent adaptation of all educational offers to the specificities of the labor market. This will increase the chances of insertion and will enhance the personal success that will ultimately lead to a social welfare. So universities will have to change their classical educational marketing strategies.

Following analyzes on the probabilistic model applied, the paper provides benchmarks on the development of the higher education process, towards increasing the success chances of young people in life and on the labor market.

\section{Literature review}

Probability is a concept developed by an entire mathematical theory. In the following, we present briefly some basic elements of the probability theory. Random experience is an action that, in probability theory, can be repeated indefinitely. An outcome related to an experience, which, after doing it, can be said to be appearing or not, is called an event.

By marking P (A) the likelihood of achieving the event A, it is calculated as the ratio of the number of favorable cases to the realization of event $A$ and the number of possible cases.

An impossible event that can be denoted by $\phi$ is an event that does not happen at any experience. The " $\mathrm{E}$ " event is an event that happens every time we perform the random experience. Thus, it is easy to see that $\mathrm{P}(\phi)=0$, and $\mathrm{P}(\mathrm{E})=1$.

It is common in probability theory, the use of symbols established in the theory of sets: $\in, \cap, \cup, \subset$. For example, the $\cup$ sign will read it "reunited" or "or". Without going into detail, we just remember that between "set theory" and "probability theory" the specialists admit there is a "duality" relationship.

Therefore, the lowest value of $\mathrm{P}(\mathrm{A})$ is 0 , if $\mathrm{A}$ is the impossible event, and the highest is 1 , if $\mathrm{A}$ is the safe event.

Either two marked events A and B.

AUB (we read "A or B" or "A reunited with B") is the event whose generation means producing at least one of the two events, $\mathrm{A}$ or $\mathrm{B}$.

$\mathrm{A} \cap \mathrm{B}$ (we read "A and B" or "A intersected with B") is the event that consists of simultaneously producing events A and B.

The event named $\bar{A}$ is called an event contrary to $\mathrm{A}$. The realization of the event $\overline{\mathrm{A}}$ assumes the failure of the event A and each other. Events A and B are called compatible, if they can occur simultaneously. Otherwise they are incompatible.

If $\mathrm{A}$ and $\mathrm{B}$ are incompatible $\mathrm{P}(\mathrm{A} \cap \mathrm{B})=0$ 
Events $\mathrm{A}$ and $\mathrm{B}$ are by definition independent if:

$\mathrm{P}(\mathrm{A} \cap \mathrm{B})=\mathrm{P}(\mathrm{A}) * \mathrm{P}(\mathrm{B})$

The notions presented above are the basis for understanding how to apply the proposed model, but also for demonstrating relationships such as formula (8). In this formula (8), the application works only to independent events.

The considerations to be applied in the paper have as a central idea that a decision regarding a certain phenomenon (the decision to choose a certain academic brand) depends on the endogenous factors, the individual's own - the human factor (the attitude of the decision maker towards higher education, than a higher education institution's brand), as well as exogenous factors (the external dimensions of the brand). These factors are inherent to the phenomenon in question.

In the model proposed by Rasch with reference to solving the items, the solving decisions may be diverse. There are similarities between the item solving situation and the buying decision making process given in the first place by the two factors mentioned.

After, Stan (2000), models based on assessments in the field of social sciences (especially psychology) are classified into deterministic and probabilistic models. After another criterion, the models are classified into multidimensional and onedimensional way.

The same author states that "in the probabilistic optic", assuming that "if the individual dominates the item, that means, he/she is able to overcome the difficulty of the item, it is likely that its scale value to be greater than that of the item (the ordering of the values on the Van der Ven scale)." Still quoting Stan, we conclude on the probabilistic model that it "builds on the hypothesis that endogenous psychological features as a latent dimension cannot be at the same level as observable behavior." (e.g. - registration at a university or another). In other words, observable behavior, the measure of which is the basis of many decisions making, is only a part of the hidden reality of human nature, impossible to be known. Closer to the truth, the measure of latent dimension - endogenous dimension, should be considered in probability terms. The statements raised from the perspective of human nature, with a direct reference to the involved psychic traits are the same in the case of solving items, as in the case of buying decisions.

Marketing theorists have developed a general and step-by-step model for purchasing decision-making, starting from cognitive theory. However, consumers often do not go through all five stages of the buying process, sometimes they will jump over or intersect. Depending on their involvement in the purchasing act and

DE GRUYTER OPEN
Studia Universitatis "Vasile Goldis" Arad. Economics Series Vol 28 Issue 2/2018 ISSN: 1584-2339; (online) ISSN: $2285-3065$

Web: publicatii.uvvg.ro/index.php/studiaeconomia. Pages $48-69$ 
Blaga R. L., Blaga, A. (2018)

Probabilistic model on buying decision of higher education services

the complexity of the buying process, customers will go directly to the buying decision stage, jumping over the search for information stage and evaluation of alternatives stage.

After Kotler and Armstrong (2012), purchase decision is defined as "the buyer's decision about which brand to purchase." "The ability of a brand to simplify purchase decisions and reduce their purchase risks becomes invaluable", says J. Jacoby, J. C. Olson and R. Haddock (1971) in Price, Brand Name, and Product Composition Characteristics as Determinants of Perceived Quality, respectively J. Jacoby, G. Szybillo and J. Busato-Sehach (1977), in Information Acquisition Behavior in Brand Choice Situations. In expressing a purchase intention, the consumer can take five secondary decisions, of which the brand is the most important, followed by the distributor (the way the product / service gets to be communicated and delivered), the delivered quantity, the time of delivery and the method of payment (cash or credit card), shows Kotler and Keller (2008) in Marketing Management.

The arguments presented above fully justify the study's attempts to analyze the purchase decision - present as a decision to choose a brand - as the main element of the purchasing and consumption process.

The brand appeared with competition. A brand is a sales promise, an intangible value that differentiates and then positions products / services versus competition, in the target customer segment. The study of literature shows that "a brand is a product which has been effectively differentiated from others and which has been provided with a form of personality which resonates with its target customers." (Stone and Desmond, 2007) A brand is a perceptual entity that, although it has its roots in tangible reality (e.g. - attributes of the product / service and the key benefits that differentiate it from the others). Actually it reflects the perceptions and perhaps even the idiosyncrasies of the consumers (e.g. - brand features associated in the client's mind with it, company values - brands must provide values that are in the minds of most customers and the user's image), shows Kotler and Keller (2008). From a tangible perspective, the brand can report a certain level of product or service quality, so that satisfied customers can easily choose the product next time, says T. Erdem (1998) in Brand Equity as a Signaling Phenomenon. The most important power of a brand is based on its performance, not on its promotion. Initially, the brand is built on advertising and then maintained only in terms of its efficiency.

What determines the reality of a higher education brand resides in its intangible resources (reputation, history, tradition etc.), but also its tangible resources (buildings, staff, endowment and money resources etc.). Both types of resources 
influence the institution's future success in the market, its quality and performance, which forms finally the brand's power.

Of the above, we can conclude that, marketers working in the field of education and branding face particular challenges: to provide tangible elements (study programs, courses and seminars, lecture halls and seminars, laboratories and facilities, sports halls), to provide consistently high quality services (teacher's skills, his/her motivation, his/her mood), to reduce the level of uncertainty and the way which clients perceive the value of educational services (the difference between benefits and costs). All of these aspects entitle us to use in our study the brand as a more exogenous factor that influences the purchasing decision.

A person's buying choices are further influenced by four major psychological factors: motivation, perception, learning, beliefs and attitudes.

Motive (drive) is "need that is sufficiently pressing to direct the person to seek satisfaction of the need." (Kotler and Armstrong, 2012)

Because of the predominantly intangible nature of education, Vorzsák Á. et al. (2004), said it should be presented through elements that can be perceived through the five senses (meeting with the teacher, the course hall/seminar hall, the atmosphere of the course and generated by the other students). Perception as the essential process of purchasing and consumption behavior is also found in determining the quality and performance of higher educational services and assessing the value or the quality - value ratio of those services.

Kotler and Armstrong (2012) mentioned about learning "changes in an individual's behaviour arising from experience. „Learning theorists say that most human behavior is learned.

Attitude is an important concept to understand because it divides cognitive from behaviorist explanations of consumer behavior, said Stone and Desmond (2007). Attitude is defined by Kotler and Armstrong (2012) like "a person's consistently favorable or unfavorable evaluations, feelings, and tendencies towards an object or idea; attitudes are difficult to change." The notion that attitude is a predisposition to behave is interesting to marketers because, if the situation is right, then a positive attitude towards a product or service should lead to an intention to buy it. Attitudes are consistent, but most importantly they are evaluative, summing up what is believed and felt about attitude objects.

It is known that choosing one university or another, it does not only express initial motivations, immediate preoccupations and aspirations, or the judgment of a brand in the decision-making process, but also reflects deep, general and stable attitudes towards education and organization of society. Last but not least, the socio-cultural values of an individual, particularly, his attitudes towards work, money, success, consumption, fun and morals, complement the series of elements which form

Studia Universitatis "Vasile Goldis" Arad. Economics Series Vol 28 Issue 2/2018 ISSN: 1584-2339; (online) ISSN: 2285 - 3065

Web: publicatii.uvvg.ro/index.php/studiaeconomia. Pages $48-69$ 
Blaga R. L., Blaga, A. (2018)

Probabilistic model on buying decision of higher education services

attitudes towards education and registration to a higher education institutions, as an endogenous factor to be studied.

\section{Research methodology}

The model of Rasch, on which our considerations are based on the decision to purchase higher education services, is based on the observation that the chance of success in a certain activity of purchasing, solving a problem in education or solving of an item in a psychological test depends on certain properties of endogenous nature. They are related to the individual involved, but also to certain characteristics of the object or service concerned, of an exogenous nature.

Currently, Rasch's model is related to the answer to an item. According to $\mathrm{H}$. Vorkauf (1978), the chance to respond correctly to an item is even greater as the respondent has skills in the field in which the item is formulated, and easier, the item is. The chance of a fair answer, but also the chance to make a correct purchase decision is expressed by:

$$
\mathrm{S}=\mathrm{a}_{\mathrm{k}} * \mathrm{f}_{\mathrm{i}}
$$

where $a_{k}$ is the buying decision ability of $\mathrm{k}$ person, assimilated to the person's attitude towards education and registration at university, and $f_{i}$ is the feature of $i$ item and it is assimilated to the university's brand.

Using formula (4) we defines the probability of realization of $\mathrm{A}$, the event of the correct answer to the item $\mathrm{i}$ by the individual $\mathrm{k}$ or, in the case of buying decision, the event of registration at university by purchasing the education service.

$$
P(A)=a_{k} * f_{i} /\left(1+a_{k} * f_{i}\right)
$$

Included in the item response theory, Rasch's model satisfies the following axioms:

1. An individual's performance on a test (buying decision) can be anticipated by a set of factors;

2. Individual performance when solving an item (buying decision) can be described by an ascending monotonous function, called curve or characteristic function of the item.

The hypothesis of unidimensionality and that of local independence complements the conditions in which the response to item theory works. Unidimensionality asserts that only one skill, in our case a single endogenous factor specific to the client (student) - the attitude - can be measured by items. In order to observe the unidimensionality, it is accepted that the performances of the individual can be explained by the existence of a dominant feature. This requirement supports the 
argument of choosing the client's attitude as a dominant feature that determines buying behavior. A person's attitude is characterized by stability, generally acquired through learning, represent what individual positively or negatively affects about things, people, processes. Local independence implies that the response to an item is not influenced by the response to another item (purchase decision against another service of this kind). The hypothesis is important because it results in the use of formula (3) that applies only to independent events. By means of elementary transformations and by using notations, the formula (5) adapted to Stan (2000) becomes:

$$
P_{i}(\theta)=e^{(\theta-b i)} /\left(1+e^{(\theta-b i)}\right)
$$

where $P_{i}(\theta)$ is the likelihood that an individual with the latent trait of value $\theta$ (the attitude) will answer to item $i$ (the buying decision which relates to the choice of brands), which has also the parameter difficulty $b_{i}$ (the brand itself), and $e$ is the Neper constant (the basis of the natural logarithm).

From the way the relation $\mathrm{P}_{\mathrm{i}}(\theta)$ was constructed, it is seen that it defines a variable function $\theta$ on the maximum definition domain $\mathbb{R}$ with values $[0,1]$. In addition, it is easy to demonstrate that the function is incrementally increasing (using, e.g. the first derivative). The graph of the function (6) with the parameter $b_{i}$ fixed is called the characteristic curve of the item and is represented in figure no.1.

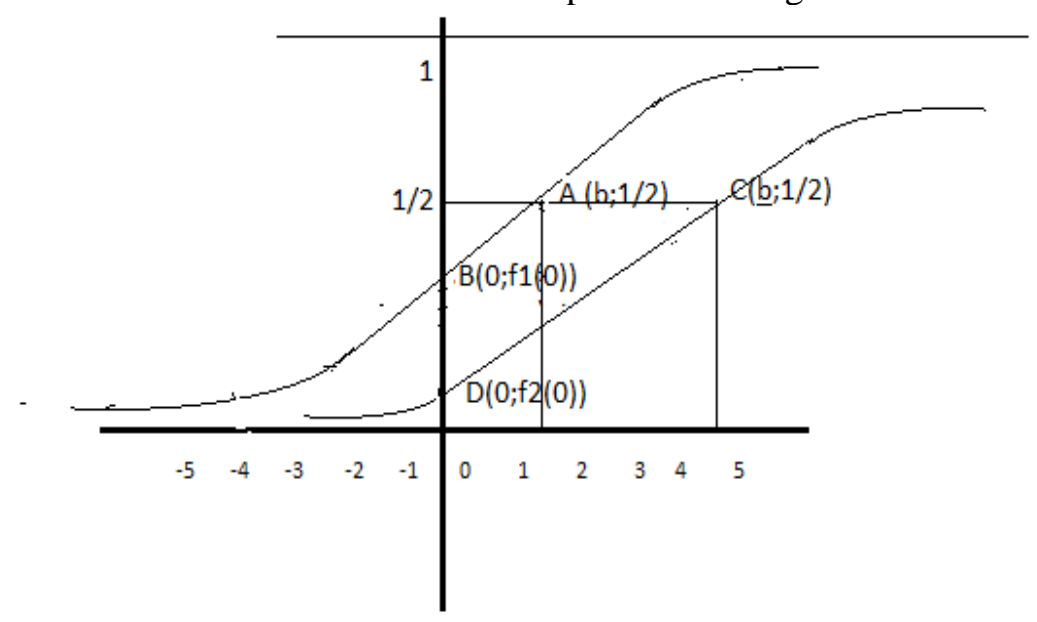

Figure 1. The graphs of functions that express - the likelihood that an individual makes the decision to choose a higher education service (registration at university) with a certain brand

Source: Author's self-processing.

DE GRUYTER OPEN
Studia Universitatis "Vasile Goldis" Arad. Economics Series Vol 28 Issue 2/2018 ISSN: 1584-2339; (online) ISSN: 2285 - 3065 
The abscissa axis is the latent trait - the endogenous factor $\theta$, and on the ordinate axis the probability that an individual makes buying decision on a particular educational service offered by a certain university. The graphical representation in figure no. 1, presents some important features.

By simplifying writing, we will note the function (6) by:

$$
f: \mathbb{R} \rightarrow[0 ; 1] \quad f(\theta)=e^{(\theta-b)} /\left(1+e^{(\theta-b)}\right)
$$

We will make some clarifications using the shape of the function graph (7). The calculation of the bounds of function (7) to $-\infty$ and respect $+\infty$ leads to the finding of horizontal asymptotes $\mathrm{y}=0$ and $\mathrm{y}=1$, and the first derivative, $\mathrm{f}^{\mid}(\theta)=\mathrm{e}^{(\theta-\mathrm{b})}$ / $\left(1+\mathrm{e}^{(\theta-\mathrm{b})}\right)^{2}$ strictly positive, leads to the conclusion that the function is steadily increasing. The function graph intersects the axis $\mathrm{Oy}$ at point $\mathrm{B}(0, \mathrm{f}(0))$, where $\mathrm{f}$ $(0)=1 /\left(1+e^{b}\right)$. From the expression of the second derivative $f^{\|}(\theta)=e^{(\theta-b)}\left(1-e^{(\theta}\right.$ - b) $) /\left(1+\mathrm{e}^{(\theta-b)}\right)^{3}$ and its sign study, result that the graph of the function accepts a single point of inflection $\mathrm{A}(\mathrm{b} ; 1 / 2)$ (see figure no. 1 ).

Returning to the expression in form (6), we will approach a method of determining the "item difficulty" parameter, assimilated in this situation with the university brand. H. Vorkauf (1978), quoting Fischer (1974) in the Einführung in the psychological test, proposes the method called Fischer's explicit method and demonstrates the formula using the elementary relationships of the probability theory already mentioned in this study. After Fischer, the facility index of item $j, f_{j}$ is:

$$
\mathrm{f}_{\mathrm{j}}=\left\{\prod_{\substack{j=1 \\ j \neq i}}^{k} \frac{n_{i j}}{n j i}\right\}^{1 / \mathrm{k}}
$$

where $n_{i j}$ is the number of individuals with the correct answer to item $i$, and the wrong answer to item $j ; n_{j i}$ is the number of individuals with the correct answer to item $j$, and the wrong answer to the item $i, k$ is the number of items. The explicit method proves to be easy to apply and is useful in any situation where the facility indexes (the exogenous factor), cannot be calculated directly.

Next, we translate Rasch's model into the buying decision study, given the isometry of the two situations. We will use the function expressed in formula (6) to determine the probability that a client (student) having a certain attitude towards education and will registrate at university (to acquire a higher educational service). In other words, if the instrument used measures the phenomenon for which it was built - the likelihood of making the buying decision? We recall that Rasch's model is a probabilistic model that refers to items which in practice are associated with a 
correct or wrong answer (e.g. - the customer buys/register at the university or does not register at the university).

The probability of responding to the item depends on the individual's endogenous parameter (attitude) and the exogenous parameter (university's brand). In addition, the model involves the acceptance of some postulates that have already been mentioned.

In the case of a buying decision (e.g. - registration at the university), the buyer answers the offer (the item in the model), accepting it or rejecting it. This prevailing attitude factor has certain specific features, described in the pages of the paper that gives it stability, but also influence the behavior of the client. Moreover, attitude research involves more than an evaluation (Stone and Desmond, 2007).

Researchers have evolved different methods for measuring attitudes, however, these have proved difficult to produce and implement so that more commonly within marketing research there has been a move towards approximating the scales, using the methods introduced by Likert. The Likert scale attempts to quantify the attitude that the individual has towards the product or service. Each student is asked not only if he/she agrees or disagrees with a given statement, e.g. "Registration at universities and continuing higher education studies increase my chances of employability on the labor market and ensure personal success.", but also the extent of the agreement, by choosing one of five categories. The categories are given scores that allow quantified measures to be made, like:

$\begin{array}{lllllll}\text { Totally } & 1 & 2 & 3 & 4 & 5 & \text { Totally } \\ \text { disagree } & \square & \square & \square & \square & \square & \text { agree }\end{array}$

Indicate on a scale of 1 (total disagreement) to 5 (total agreement), if you approve or disapprove the following statement: "Registration at universities and continuing higher education studies increase my chances of employability on the labor market and ensure personal success."

The quality and performance of the top-level educational service, that is going to be purchased is provided by the brand of the institution. It is the second factor, the exogenous parameter in correlation with the attitude of the individual, on which buying decision depends. Global evaluation of the university's brand can be done quite simply by involving them in an increasing form of preferences. This could be obtained by means of a question such as:

Which of the following universities do you prefer?

Arrange in the order of increasing preferences the following universities (1 - least favorite and 4 - most preferred):

University no.1 $\square \quad$ University no.2 $\square \quad$ University no.3 $\square \quad$ University no.4 
Using scalar evaluation methods (ordinate scales), the two factors can be evaluated: hexogen $\left(b_{i}\right)$ and endogen $\theta$. It will then determine $P_{i}(\theta)$ - the likelihood that an individual with the latent trait of $\theta$ value (the attitude, endogenous factor of buying decision) will respond to item $i$ (buying decision referring to the brands that can be bought), which has the difficulty parameter $b_{i}$ (exogenous factor - the brand itself). The index takes values from the crowd $\{1,2,3$, and 4$\}$.

\section{Findings}

We further admit that we have four above noted universities that offers higher education services (master and bachelor) in the same specialties. We will establish the exogenous parameter university brand, the parameter $b_{i}$ from Rasch model, using Fischer's explicit method and the scalar evaluation mode of preference for that brand. The evaluation is done on a group of 244 high school graduates, asked to do each a hierarchy of preference to the 4 universities, in ascending order, using their own experiences and information. If a graduate, for example, classifies universities in the order of University no. 1 (the least preferred), University no. 3, University no. 4, University no. 2 (most preferred), the result will be recorded conventionally by $\left(1,2^{-}\right)$. We synthesize the results in the table:

Table 1. The hierarchy of preferences for university's brands

\begin{tabular}{|c|c|c|c|c|}
\hline $\begin{array}{c}\text { Favorite university } \\
\text { The least preferred university }\end{array}$ & $\mathbf{1}^{-}$ & $\mathbf{2}^{-}$ & $\mathbf{3}^{-}$ & $\mathbf{4}^{-}$ \\
\hline $\mathbf{1}$ & - & 9 & 2 & 2 \\
\hline $\mathbf{2}$ & 30 & - & 9 & 3 \\
\hline $\mathbf{3}$ & 41 & 27 & - & 6 \\
\hline $\mathbf{4}$ & 56 & 37 & 22 & - \\
\hline
\end{tabular}

Source: Author's self-processing.

The results in the table are interpreted as follows: e.g. - figure 9 in line 1, column $2^{-}$, shows that 9 of the respondents are of the opinion that University no. 1 is the least preferred, and University no. 2 is the most preferred one.

In turn, formula (8) is applied to each university, determining the brand's appreciation (the smallest value of $f_{j}$ - showed the brand is the most appreciated and revers):

$$
\begin{aligned}
& \mathrm{b}_{1}=[(9 * 2 * 2) /(30 * 41 * 56)]^{1 / 4}=0,1512 \\
& \mathrm{~b}_{2}=[(30 * 9 * 3) /(9 * 27 * 37)]^{1 / 4}=0,5478 \\
& \mathrm{~b}_{3}=[(41 * 27 * 6) /(2 * 9 * 22)]^{1 / 4}=2,0237 \\
& \mathrm{~b}_{4}=[(56 * 37 * 22) /(2 * 3 * 6)]^{1 / 4}=5,9652
\end{aligned}
$$


The structure that we have proposed - the function that expresses the likelihood that a higher educational service is chosen by a candidate, needs the expression of a parameter. This is attitude towards education and higher education in ensuring professional and personal success or, in other words, the element determining a person to register to university.

As shown, the parameter "brand university" note $b_{i}$ on the formula (6) is already calculated for each university independently of the individual that purchase the educational service, because respondents were not asked to imagine that they would register at university. They ranked the preferences for one university to another in increasing order. Therefore, the persons who purchase the educational service may be the same or other than those who participated in the determination of the value $b_{i}$, (brand). In the case of people who evaluate their attitude (value of $\theta$ ), the question puts determine direct involvement in the subject approached. It follows from the calculations of formula (8) that the appreciation of the university's brands considered increases from University no. 4, the least appreciated, to University no. 1, preferred as a brand. Each university corresponds to a characteristic function of the following type:

$$
\mathrm{P}_{\mathrm{i}}: \mathbb{R} \rightarrow[0 ; 1] \quad \mathrm{P}_{\mathrm{i}}(\theta)=\mathrm{e}^{\left(\theta-\mathrm{b}_{\mathrm{i}}\right)} /\left(1+\mathrm{e}^{\left(\theta-\mathrm{b}_{\mathrm{i}}\right)}\right)
$$

so:

$$
\begin{aligned}
& \mathrm{P}_{1}(\theta)=\mathrm{e}^{(\theta-0,1512)} /\left(1+\mathrm{e}^{(\theta-0,1512)}\right) \\
& \mathrm{P}_{2}(\theta)=\mathrm{e}^{(\theta-0,5478)} /\left(1+\mathrm{e}^{(\theta-0,54782)}\right) \\
& \mathrm{P}_{3}(\theta)=\mathrm{e}^{(\theta-2,0237)} /\left(1+\mathrm{e}^{(\theta-2,0237)}\right) \\
& \mathrm{P}_{4}(\theta)=\mathrm{e}^{(\theta-5,9652)} /\left(1+\mathrm{e}^{(\theta-5,9652)}\right)
\end{aligned}
$$

In brief, choosing a brand generally depends on the service itself and the key benefits that has already mentioned. The choice of the brand also involves the degree of determination of the person that make the decision, its latent feature, of which the most dominant feature is the attitude, followed by motivation, perception, earning.

The probability of choosing a particular educational service is expressed by function (13). The functions (14), (15), (16), (17) attached to the four graphically represented universities each characterize the probability that their educational services attract more or fewer beneficiaries. They can be characterized by different levels of determination, expressed through the probability of acquiring the educational service.

Table no. 2, presented above, is a spreadsheet, made to determine the probability of enrolling in a particular university. The four characteristic functions (14), (15), 
Blaga R. L., Blaga, A. (2018)

Probabilistic model on buying decision of higher education services

(16), (17) are used for values of $\theta: 1,2,3,4$ and 5, expressed on the Likert scale. The last two columns of the table highlight the final results that are included in table no. 3 - conclusions.

Table 2. Running calculations to determine the likelihood of enrolling at university that has a certain brand

\begin{tabular}{|c|c|c|c|c|c|c|c|c|}
\hline$\theta$ & $-\mathbf{b i}$ & $\theta-\mathbf{b i}$ & bi) & $\mathbf{K}^{*}$ & $1+e^{(\theta-b i)}$ & $\begin{array}{l}G= \\
1 /\left(1+e^{(\theta-b i)}\right)\end{array}$ & $\begin{array}{l}\text { Prod } \\
\text { DxG }\end{array}$ & $\begin{array}{l}\text { Funct. } \\
\text { Value }\end{array}$ \\
\hline 1 & $-0,1512$ & 0,8488 & 2,336841 & 1 & 3,336841 & 0,299685 & 0,700315 & P1(1) \\
\hline 1 & $-0,5478$ & 0,4522 & 1,571766 & 1 & 2,571766 & 0,388838 & 0,611162 & P2(1) \\
\hline 1 & $-2,0237$ & $-1,0237$ & 0,359263 & 1 & 1,359263 & 0,735693 & $\mathbf{0 , 2 6 4 3 0 7}$ & P3(1) \\
\hline 1 & $-5,9652$ & $-4,9652$ & 0,006977 & 1 & 1,006977 & 0,993072 & 0,006928 & P4(1) \\
\hline 2 & $-0,1512$ & 1,8488 & 6,352192 & 1 & 7,352192 & 0,136014 & $\mathbf{0 , 8 6 3 9 8 6}$ & P1(2) \\
\hline 2 & $-0,5478$ & 1,4522 & 4,272504 & 1 & 5,272504 & 0,189663 & $\mathbf{0 , 8 1 0 3 3 7}$ & P2(2) \\
\hline 2 & $-2,0237$ & $-0,0237$ & 0,976579 & 1 & 1,976579 & 0,505925 & 0,494075 & P3(2) \\
\hline 2 & $-5,9652$ & $-3,9652$ & 0,018964 & 1 & 1,018964 & 0,981389 & 0,018611 & P4(2) \\
\hline 3 & $-0,1512$ & 2,8488 & 17,26705 & 1 & 18,26705 & 0,054743 & $\mathbf{0 , 9 4 5 2 5 7}$ & P1(3) \\
\hline 3 & $-0,5478$ & 2,4522 & 11,61387 & 1 & 12,61387 & 0,079278 & 0,920722 & P2(3) \\
\hline 3 & $-2,0237$ & 0,9763 & 2,654616 & 1 & 3,654616 & 0,273627 & 0,726373 & P3(3) \\
\hline 3 & $-5,9652$ & $-2,9652$ & 0,05155 & 1 & 1,05155 & 0,950977 & 0,049023 & P4(3) \\
\hline 4 & $-0,1512$ & 3,8488 & 46,93671 & 1 & 47,93671 & 0,020861 & $\mathbf{0 , 9 7 9 1 3 9}$ & P1(4) \\
\hline 4 & $-0,5478$ & 3,4522 & 31,56977 & 1 & 32,56977 & 0,030703 & $\mathbf{0 , 9 6 9 2 9 7}$ & P2(4) \\
\hline 4 & $-2,0237$ & 1,9763 & 7,215994 & 1 & 8,215994 & 0,121714 & 0,878286 & P3(4) \\
\hline 4 & $-5,9652$ & $-1,9652$ & 0,140128 & 1 & 1,140128 & 0,877095 & 0,122905 & P4(4) \\
\hline 5 & $-0,1512$ & 4,8488 & 127,5872 & 1 & 128,5872 & 0,007777 & 0,992223 & P1(5) \\
\hline 5 & $-0,5478$ & 4,4522 & 85,81553 & 1 & 86,81553 & 0,011519 & $\mathbf{0 , 9 8 8 4 8 1}$ & P2(5) \\
\hline 5 & $-2,0237$ & 2,9763 & 19,61511 & 1 & 20,61511 & 0,048508 & 0,951492 & P3(5) \\
\hline 5 & $-5,9652$ & $-0,9652$ & 0,380907 & 1 & 1,380907 & 0,724162 & $\mathbf{0 , 2 7 5 8 3 8}$ & P4(5) \\
\hline
\end{tabular}

Source: Author's self-processing. 
Blaga R. L., Blaga, A. (2018)

Probabilistic model on buying decision of higher education services

The first line in table no. 2, for example, shows intermediate results and the final result for P1 (1) calculated by formula (14), written in the form P1 (1) = DxG, where $D$ and $G$ are the notations in the table head of the table no. 2. Similar explanations, we could give for other lines of table no. 2. Tables no. 3 are value tables for the $\mathrm{P} 1(\theta), \mathrm{P} 2(\theta), \mathrm{P} 3(\theta)$ and $\mathrm{P} 4(\theta)$ functions to represent points (5 points for each function). The four graphs are shown in figure no. 2.

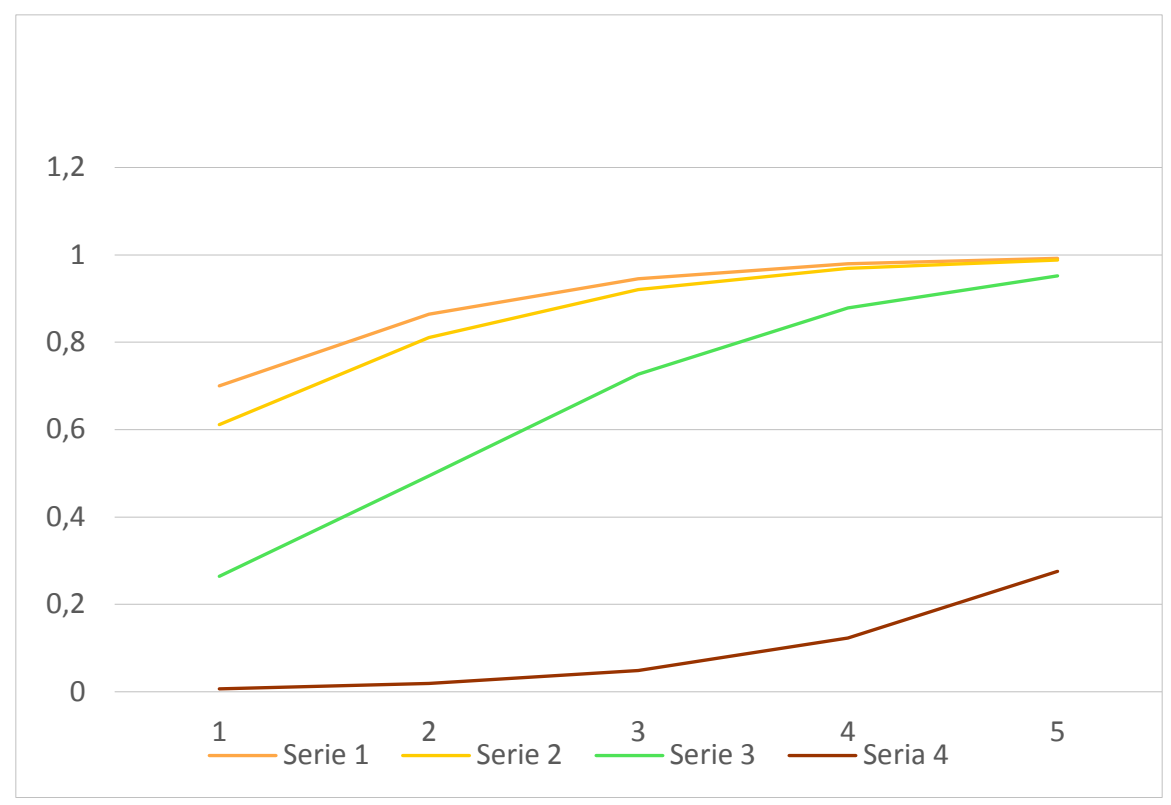

Figure 2. The graphs of characteristic functions of the four university's brands [1] Source: Author's self-processing.

It is worth mentioning that in the construction of the 4 charts, were used the points in the tables below:

Table 3. The values table of characteristic functions of four universities

\begin{tabular}{|c|l|l|l|l|l|}
\hline $\begin{array}{c}\text { Atitude } \\
\boldsymbol{\theta}\end{array}$ & \multicolumn{1}{|c|}{$\mathbf{1}$} & $\mathbf{2}$ & $\mathbf{3}$ & $\mathbf{4}$ & $\mathbf{5}$ \\
\hline $\mathbf{P}_{\mathbf{1}}(\boldsymbol{\theta})$ & 0,700315 & 0,863986148 & 0,94525662 & 0,979139159 & 0,992223176 \\
\hline $\mathbf{P}_{\mathbf{2}}(\boldsymbol{\theta})$ & 0,611162176 & 0,810336785 & 0,920722184 & 0,969296682 & 0,988481324 \\
\hline $\mathbf{P}_{\mathbf{3}}(\boldsymbol{\theta})$ & 0,264307312 & 0,494075277 & 0,726373439 & 0,878286187 & 0,951491882 \\
\hline $\mathbf{P}_{\mathbf{4}}(\boldsymbol{\theta})$ & 0,00692822 & 0,018611294 & 0,049023014 & 0,122905389 & 0,275838277 \\
\hline
\end{tabular}

Source: Author's self-processing.

DE GRUYTER OPEN
Studia Universitatis "Vasile Goldis" Arad. Economics Series Vol 28 Issue 2/2018 ISSN: 1584-2339; (online) ISSN: 2285 - 3065 
The study develops applications of Rasch's model, showing results for educational marketers about the likely behavioral situations in which potential clients of higher educational services can be found. However, this research has some limitations that we will describe in the following:

- the unidimensionality of the model, which involves the acceptance of only one factor endogenous; factors such as: motivation, perception, learning - very important in making the buying decision are not accepted in modeling due to unidimensionality;

- attitude, as a factor is desirable to be analyzed in depth (emotional, rational, cognitive), the proposed model cannot do such analysis;

- brand as an exogenous factor of analysis, although originated in the tangible reality, studies show that it is at the same time a fact that resides in the minds of consumers, and the model cannot approach this hue;

- the study shows a certain degree of subjectivism induced in the writing of functions characteristic of each product or service, by individuals expressing their preferences included in the primary data of constants construction, by the method proposed by H. Vorkauf;

- the study presents purchasing decisions (choice) of the higher educational services expressed in a probable manner, so to an extent that we may consider imprecise;

- the study induces the need to periodically update market investigations in educational field with costs that may be quite high.

\section{Discussion}

Here are some practical references for the Rasch's model and some conclusions. Writing the characteristic functions of each university's brand according to formula (7) ensures the application of the probability model in the study of the customer buying decision. Choosing a sample of potential customers to pronounce on brands (constant b) is a recommended measure. Calculation of constants $b$ can be done with the method proposed by $\mathrm{H}$. Vorkauf by applying formula (8).

Characteristic function determined for multiple universities' brands can be represented graphically. They emphasize the ability to discriminate between different brands. In relation to the construct presented above, behavioral, cognitive and involvement theories we can identify and describe some likely behavioral situations in which customers (high school graduate) can find themselves.

The point with coordinates $\mathrm{b}$ and 0,5 for a given characteristic function is an important point in the graph, which we will call a critical point. Let us return to the functions $\mathrm{P} 2(\theta)$ and $\mathrm{P} 3(\theta)$ graphically represented in figure no. 3, to analyze and 
propose some marketing strategies. Characteristic functions represented graphically are:

$$
\begin{aligned}
& \mathrm{P}_{2}(\theta)=\mathrm{e}^{(\theta-0,5478)} /\left(1+\mathrm{e}^{(\theta-0,54782)}\right) \\
& \mathrm{P}_{3}(\theta)=\mathrm{e}^{(\theta-2,0237)} /\left(1+\mathrm{e}^{(\theta-2,0237)}\right)
\end{aligned}
$$

For two brands in competition - e.g., one weaker and another stronger like in figure no. 3, the utility of the model presented in the study is that it provides punctual solutions in concrete cases.

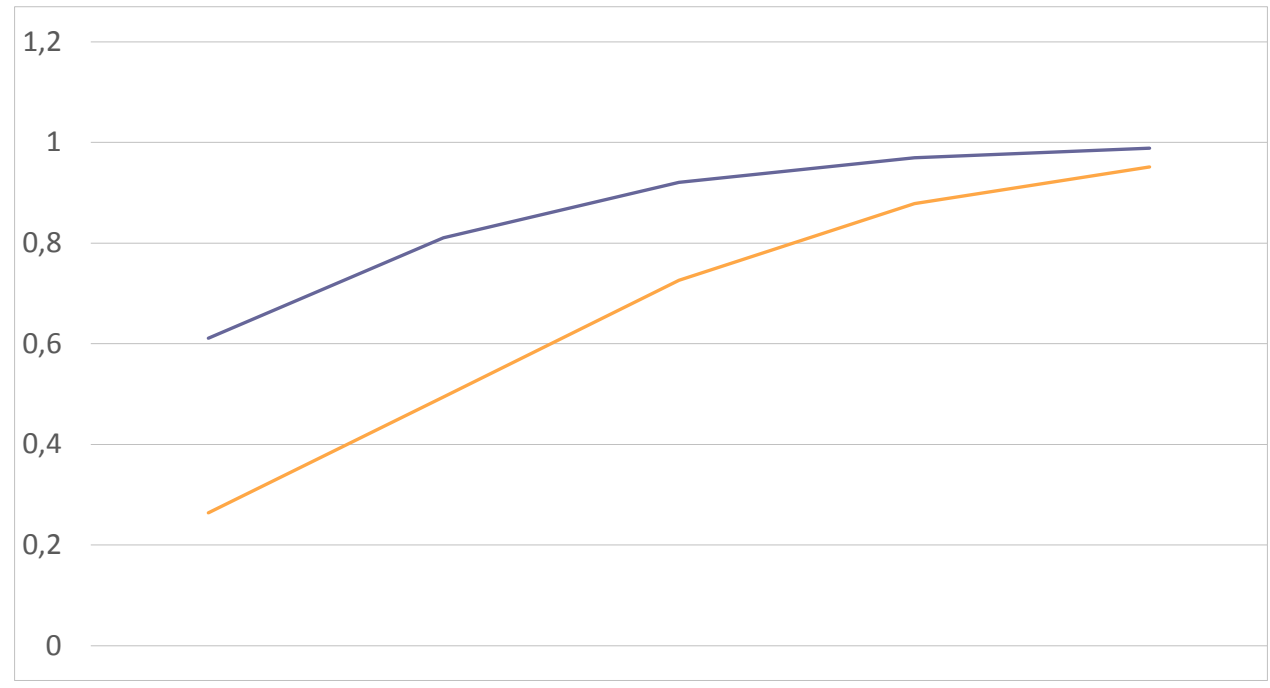

Figure 3. The graphs of characteristic functions of the $P_{2}$ and $P_{3}$ university's brand Source: Author's self-processing

The purpose of the marketing measures applied in practice should be that, for the same buyer with the endogen $\theta$, the probability of making the buying decision, $\mathrm{P}_{2}$ $(\theta)$ and $P_{3}(\theta)$, is very close. Speaking in probability terms, that is the situation would benefit the weaker brand.

Figure no. 3 suggests a way of action for the weaker brand, the approaching of the graph $\mathrm{P}_{3}(\theta)$ by the graph $\mathrm{P}_{2}(\theta)$, possibly intersecting it and its overcoming. This strategic approach involves measures to increase the weaker brand. Also, as a measure of action of the weaker brand, the action of increasing the variable $\theta$ - the endogenic factor (its position to the right on the axis of the abscissae), by specific public policies, leads to this value $\theta$, to the approximation of probability values $\mathrm{P}_{3}$ 
$(\theta)$ and $P_{2}(\theta)$. We will refer to function $P_{3}(\theta)$, if the brand growth policies do not apply, so the positions of the two charts do not change.

We admit that the buying decision is theoretically appropriate, meaning it can be difficult to reverse, if the probability given by the characteristic functions is equal to or exceeds 0,5 - critical value of buying decision. It will be noticed that in the case of the weaker brand, in figure no. 3 , if $P_{3}(\theta)=0,5$, then $\theta=2,0237$, so the critical point has the coordinates $(2,0237$ and 0,5$)$. Hence, the practical conclusion is that for a weaker university's brand, marketing policies will focus on potential customers with less valuable endogenous factor, in order to increase their endogenous factor, over the value of $\theta=2,0237$.

Characteristic functions determined for multiple brands can be represented graphically. Interpreting graphs may suggest benchmarks in defining marketing strategies. Monitoring the effects of these strategies under the new conditions, can be done by studying new, distinctive features for each individual university's brand.

Some policies of influencing potential buyers from the Rasch model perspective can be explained using figure no.4. It explains the relationship between individuals who choose to buy educational services from the brand defined by function $F_{1}$ or from the brand defined by function $F_{2}$. The critical point of the function $\mathrm{F}_{1}$ is $\mathrm{A}(\mathrm{b}$; $1 / 2)$, and the function of $\mathrm{F}_{2}$ is $\mathrm{C}(\underline{\mathrm{b}} ; 1 / 2)$.

We notice that the interval $[\underline{b} ; \infty)$ is included in the interval $[b ; \infty)$. The two intervals contain values of the endogenous factor $\theta$ (attitude), specific to each buyer. The university weaker brand, represented by $F_{2}$, should focus their marketing strategies towards that segment of customers who although had a purchasing decision for defining the university's brand $F_{1}$ did not make the choice for various reasons. They could be persuaded to choose the educational services of the university's brand described by $\mathrm{F}_{2}$.

It is recommended to find buyers who were likely to purchase more than $1 / 2$ for $F_{1}$, but have not completed it. For them, endogenous factor $\theta$ (attitude) can be modified by specific public and marketing policies. They can be included in the range of [ $\underline{\mathrm{b}} ; \infty)$. Thus the probability $F_{2}(\theta)$ will become big enough to ensure the purchase of the services offered by the $F_{2}$ brand of the university 


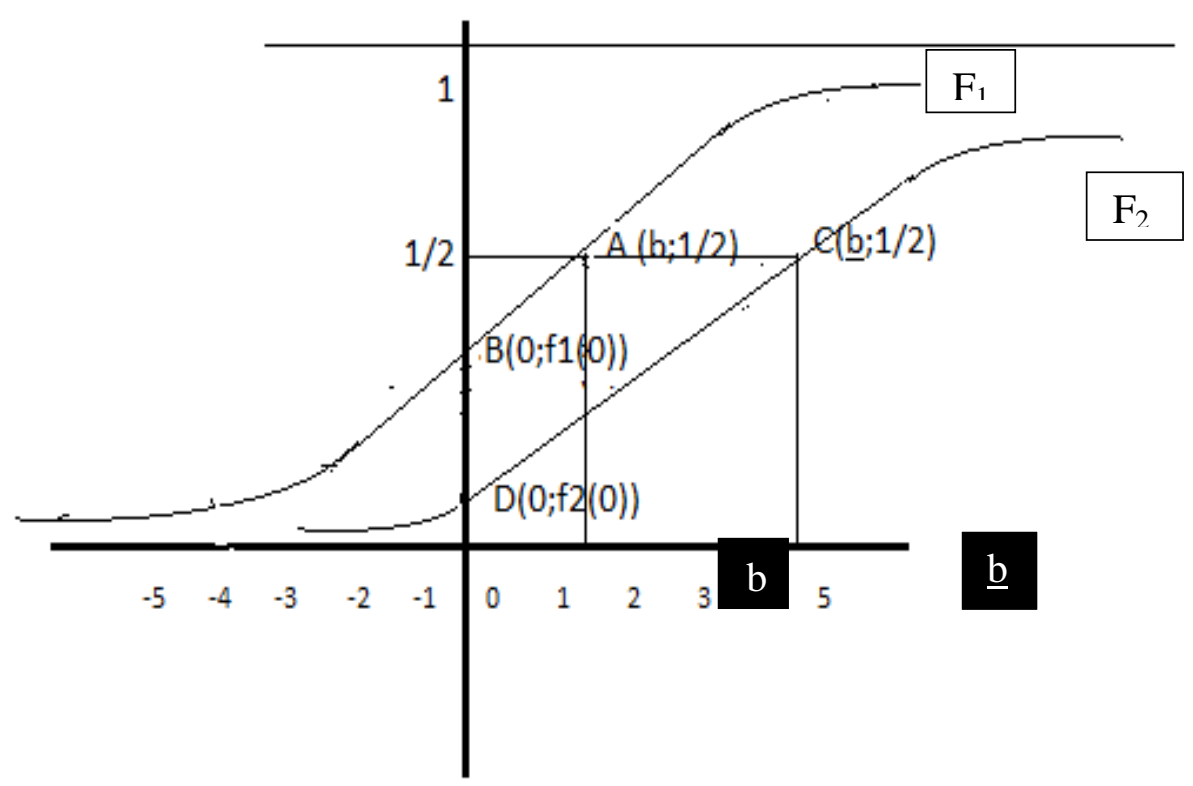

Figure 4. The graphs of two characteristic functions of different university's brands Source: Author's self-processing

Taking the critical point of a characteristic functions as a benchmark, some remarks can be made regarding buying decision of higher educational services:

1. The high involvement buying decision behavior of respondents (high school

graduates) whose attitude towards education and professional success is at the level associated with each brand specific function, over the value of $\theta=\mathrm{b}$. This leads to a high probability (over 50\%) of buying / choice of a university's brand. This category of potential customers are involved in the purchase process, are educated and advised. They are determined of pursuing higher education institution. To this aim, they try to solve the issue of university admission as best as possible, searching for and evaluating specific information.

The deeply involved buying behavior of this type of consumer is because they are aware of the value of investing in education and the role of choosing a good academic brand for their personal and professional success. The higher educational service is important to the client of this type because he has a critical role in representing his own identities (What do others think about me? - known as „badge value"; What do others think about the value of the university's brand? What is the importance of the risk that I assume, if I fail to enter the labor market after 
graduation?). By deep involvement in the buying decision, the client (the high school graduate) goes through several stages of the purchasing process: trust, understanding, and retention of the aspects that characterize the university's brand (study programs, facilities offered by university's campus, in particular consulting services, professional counseling, scholarships, motivational courses etc.) In the case of the deeply involved purchasing behavior it is expected that due to the favorable attitude towards education in ensuring personal and professional success, the client (the high school graduate) will look for the intangible elements of the university in which he will find himself (beliefs, attitudes and feelings), thus forming his clear intention to enroll in the university with the specific brand.

2. The low involvement buying decision behavior of respondents (high school graduates) whose attitude towards education and professional success is at the level associated to each brand specific function under the value of $\theta=b$. This leads to a low probability (under 50\%) of buying / choice of a university's brand. This type of behavior may be associated with a poor involvement in the decision to purchase the service, the position of the clients being a passive one, in the best case open to the receipt of information, that lead to passive learning. In the case of such a poorly engaging buying behavior, the client (the high school graduate) considers that enrolling in a university is not what he wants, it is not what himself feel, this situation it is not important to him/her and his/her image.

The purchasing process that involves a low involvement, is due to routine, the general decision process is similar: bought the product before and so do not need to carry out an intensive external search; follow the peripheral route of processing, where people use heuristics that focus on superficial aspects of the advertising that classical conditioning is the best explanation. The student is not attached to the university's brand, only if there are significant differences between the brand (study programs, additional services facilities, large scholarships and large values). Most of the time, he will evaluate the brand after registration at the university and during the years of study.

Other psychological and personal factors can influence here, buying decisions, like: learning (informal and formal), motivation (graduates enroll at the university because their friends did, because he wants to make friends, have fun, have a degree as parents want etc.), perception (the pleasant atmosphere of the university), age, lifestyle etc.

Next, we will discuss some aspects of educational marketing strategies that can be deduced from the study of the characteristic function of a brand attached to the high-rise purchase event. For this situation, educational marketing managers will have to realize that: it is the brand of the university that determines the high school graduates to follow a university or another, especially in case of those who have a 
good and very good attitude towards education and its influence on life success. A well-placed academic brand in collective memory will also increase the number of prospective clients who will choose for it, even if graduates with a less favorable attitude towards education will also come into that category. Figure no. 2 demonstrates that those who want purchase educational services of the University no. 1 - a good brand, comparative to University no. 2 - a weak brand, for the same $\theta$ value, quickly reach high values of probability, therefore greater likelihood of purchase.

It is also to be followed, the general strategic policies recommended by specialists:

- the message in defining a strong brand will need to be built based on quality and academic performance; the best-used communication environment can be the Internet (university / faculty web site), prints (brochures, leaflets, guidebooks), educational fairs and information points in the university, because those customers type (high involved in buying decision) are searching for and evaluating information;

- counseling and guidance services at the leading brand university, also there are tutors, leadership faculties who will have to endure the cognitive dissonance of the students, especially in the early years, by understanding their needs and desires. This can prevent university dropouts, a phenomenon that is increasingly noticed in the academic environment that already has a negative impact on the brand, but also on society;

- the price of services is called for, insisting more on the value of services provided (comparison of the benefits of university's brand and education costs); it will be presented payment methods and supporting investment in education;

Finally, we can say that leading brand universities and those aspiring to build a strong university's brand, must be those who are involved at national level together with the Ministry of Education in specific educational programs, like: environmental, health, financial, entrepreneurial, motivational courses, but also in professional counseling and guidance programs designed to form positive attitudes towards education in general, towards the need for lifelong learning.

\section{Conclusions}

In this paper we focus on the descriptive level marketing research, which presents in a probable way, the particular brand educational service buying decision process and the chance this could be chosen by an education and successful life individual. Using the Rasch developed model, we design a construction which links the exogenous factor - the brand of the educational service offered by university, with the endogenous factor - the attitude of an individual (high school graduate) to determine the likelihood of buying decision for the given context.

Studia Universitatis "Vasile Goldis" Arad. Economics Series Vol 28 Issue 2/2018 ISSN: 1584-2339; (online) ISSN: $2285-3065$

Web: publicatii.uvvg.ro/index.php/studiaeconomia. Pages $48-69$ 
Blaga R. L., Blaga, A. (2018)

Probabilistic model on buying decision of higher education services

Depending on these issues, the probability approach helps us to achieve a segmentation of the educational market by the university's brand and individual attitude towards education and its role in sustaining personal and professional success.

Moreover, we identify and describe two probable buying situations, determined on the strength of each brand university.

The purpose of these marketing approaches leads to the fact that for the same buyer with the same endogen factor $\theta$ (the attitude), the probability of buying decision making for two distinct university brands is very close. On probability terms speaking, this situation can benefit the weaker brand.

The proposed model offers the development and deep introducing other endogenous and / or exogenous factors research that can solve other marketing aspects regarding consumer behaviour.

\section{References}

1. Boadé, G. (2013), Robustesse du modèle de Rasch unidimensionnel à la violation de l'hypothèse d'unidimensionnalité, in http://hdl.handle.net/1866/994 [accessed on 20.02.2018]

2. Fischer, G. (1974), Einfûhrung in die psychologische Testtheorie, Bern, Ed. Huber

3. Hambleton, R. K. \& Russel, W. J. (1993), Comparison of classical test theorty and item response theory and their application to test development. Educational Measurement: Issues and practice, p. 38-47

4. Hambleton, R. K., Swaminathan, H. \& Rogers, H. J. (1991), Fundamentals of item response theory, California, SAGA publications

5. Jacoby, J., Szybillo, G. \& Busato-Sehach, J. (1977), Information Acquisition Behavior in Brand Choice Situations, Journal of Marketing Research, p. 63-69

6. Jacoby, J., Olson, J. C. \& Haddock R. (1971), Price, Brand Name, and Product Composition Characteristics as Determinants of Perceived Quality, Journal of Consumer Research 3, no. 4, p. 209-216

7. Kotler Ph., Armstrong G. (2012), Principles of marketing - 14th ed., New Jersey, Ed. Prentice Hall

8. Kotler Ph., Keller K. L., (2008), Managementul marketingului - ed. V, București, Editura Teora

9. Kotler Ph., Fox K., (1995), Strategic Marketing for Educational Institutions - second ed., New Jersey, Ed. Prentice-Hall

10. Opariuc-Dan, C., (2012), Caracteristici ale modelelor de evaluare psihologică bazate pe Teoria Răspunsului la Item in https://www.researchgate.net/profile/Cristian_Opariuc-Dan ／publication/229150476_ [accessed on 18.01.2018]

11. Stan, A, (2000), Statistică aplicată în psihologie, Iași, Editura Polirom

12. Stone, M. A., Desmond, J., (2007), Fundamentals of Marketing, London \& New York, Ed. Routledge 
Blaga R. L., Blaga, A. (2018)

Probabilistic model on buying decision of higher education services

13. Tulin Erdem, (1998), Brand Equity as a Signaling Phenomenon, Journal of Consumer Psychology 7, no.1998, p. 131-157

14. Vorzsák Á. et al. (2004), Marketingul serviciilor, Cluj-Napoca, Editura Presa Universitară Clujeană

15. Central Intelligence Agency, https://www.cia.gov/library/publications/resources/theworld-factbook/geos/ro.html [accessed on 14.02.2018]

16. Comisia Europeană - Eurostat, http://ec.europa.eu/eurostat/statisticsexplained/index.php/File:Employment,_education_and_training_status_of_young_peop le,_by_age_and_sex,_EU-28,_2016.PNG_[accessed on 14.02.2018]

17. http://www.vorkauf.ch/ Evaluation à référence critérielle: Présentation du modèle de Rasch [accessed on 20.02.2018]

\section{Notes:}

[1] The series $b_{i}$, where $b_{i}$ takes values from 1 to 4 represents the characteristic function the probability that the university having the brand $b_{i}$ will enroll clients with the attitude $\theta$

DE GRUYTER OPEN
Studia Universitatis "Vasile Goldis" Arad. Economics Series Vol 28 Issue 2/2018 ISSN: 1584-2339; (online) ISSN: $2285-3065$

Web: publicatii.uvvg.ro/index.php/studiaeconomia. Pages $48-69$ 